\title{
Study on Cr/Ag/Au Layered Electrode for AT-Cut Quartz Resonators
}

\author{
Min-Chiang Chao, Chih-Wen Lin, Jun-Nan Shang, and Chung-Lun Lo \\ TXC Corporation, Ping Cheng City, Taoyuan County, Taiwan
}

Abstract- In recent years, demand for quartz crystal resonators continues to grow for the mobile phone market. To meet the stringent long-term frequency stability requirement, crystal makers usually use $\mathrm{Au}$ as the electrode baseplating material. Using layered electrodes with different metallic materials was reported in the past for different reasons. In this paper we report our own study of using a sputtered $\mathrm{Cr} / \mathrm{Ag} / \mathrm{Au}$ layered structure for the electrodes of AT-cut quartz crystal resonators with the sole intention of reducing the usage of $\mathrm{Au}$ for cost reason. We studied the physical parameter, electrical sheet resistance, of the layers along with thermal processes. The electrical characteristics of finished crystal resonators were compared with those made with the $\mathrm{Cr} / \mathrm{Au}$ baseplated electrodes and the reliability performance of the crystals with new electrodes also be examined. Preliminary results show that AT-cut quartz crystal resonators with electrodes based on the $\mathrm{Cr} / \mathrm{Ag} / \mathrm{Au}$ layered structure meet the long-term frequency stability requirement for mobile phone application. The electrical characteristics are compatible to the $\mathrm{Cr} / \mathrm{Au}$ baseplated crystal resonators. The physical characteristics study shows that the $\mathrm{Cr} / \mathrm{Ag} / \mathrm{Au}$ layered structure is stable under related thermal process environments.

\section{INTRODUCTION}

In recent years, demand for quartz crystal resonators continues to grow for the mobile phone market. From 2003 to 2006(forecast), the mobile phone sales quantity grow from about 500 million units to over 900 million units, average annual growth rate is over 20\% [1]. However, the pressure for price down increases very fast because lowprice markets dominate the requirements, and gives high pressure on quartz crystal suppliers.

To meet the stringent long-term frequency stability requirement, crystal makers usually use $\mathrm{Au}$ as the electrode baseplating material. Using layered electrodes with different metallic materials was reported in the past for different reasons, including to improve the power durability of SAW filters[2][3][4], to improve the performance of FBARs [5], and materials characterization by using resonators [6]. In this paper we report our own study of using a sputtered $\mathrm{Cr} / \mathrm{Ag} / \mathrm{Au}$ layered structure for the electrodes of AT-cut quartz crystal resonators with the sole intention of reducing the usage of $\mathrm{Au}$ for cost reason. We studied the physical parameter, electrical sheet resistance, of the layers along with thermal processes. The electrical characteristics of finished crystal resonators were compared with those made with the $\mathrm{Cr} / \mathrm{Au}$ baseplated electrodes and the reliability performance of the crystals with new electrodes also be examined.

\section{EXPERIMENTS SETUP}

To evaluate the characteristics, electrical performance and reliability of the $\mathrm{Cr} / \mathrm{Ag} / \mathrm{Au}$ layered electrode, we setup 2 kinds of experiments, the first one is through crystal resonators, $5.0 \mathrm{~mm} \times 3.2 \mathrm{~mm}$ size $26 \mathrm{MHz}$ quartz crystal resonators as specs for mobile phone applications, and examine the 
reliability and electrical performance. The second experiment is through a 4" silicon wafer with the coated layered electrodes for characteristics evaluation, in the paper, we checked about the electrical sheet resistance. Both the crystal resonators and 4" silicon wafer past through same sputtering process and thermal processes, including curing, vacuum annealing, baking and reflow, their setup conditions are shown in table I.

Table I. The setup conditions for thermal processes

\begin{tabular}{|c|c|}
\hline Thermal Process & Setup Conditions \\
\hline Curing & $265^{\circ} \mathrm{C}, 180 \mathrm{~min}$ \\
\hline Vacuum Annealing & $295^{\circ} \mathrm{C}, 360 \mathrm{~min}$ \\
\hline Baking & $200{ }^{\circ} \mathrm{C}, 720 \mathrm{~min}$ \\
\hline Reflow & $\begin{array}{c}180^{\circ} \mathrm{C}(10 \mathrm{~min}) \& 260^{\circ} \mathrm{C} \\
\text { (peak), } 10 \mathrm{sec}\end{array}$ \\
\hline
\end{tabular}

The electrode layer structure from the base material (AT-cut quartz) is $\mathrm{Cr} 10 \mathrm{~nm}, \mathrm{Ag} 300 \mathrm{~nm}$, and $\mathrm{Au} 150 \mathrm{~nm}$.

The sheet resistance of the layered electrode was measured by 4-points probe (Resmap, IDE) through on wafer scanning probing, total 151 points data. The measurement did along with after as-deposited, and each thermal process as shown in table I.

To compare the electrical performance with usual $\mathrm{Cr} / \mathrm{Au}$ electrode crystals, $4500 \mathrm{pcs} 26 \mathrm{MHz} 5.0$ $\mathrm{x} 3.2 \mathrm{~mm}$ crystal resonators were made by using the same blank, ceramic packages and assembly processes by using $\mathrm{Cr} / \mathrm{Ag} / \mathrm{Au}$ layered electrode.

The reliability, especially the aging performance, is important for mobile applications. In this paper, we conducted 3 kinds of thermal conditions to evaluate the reliability performance including reflow, thermal shock, and high temperature and high humidity test.

\section{EXPERIMENT RESULTS}

\section{Electrical Sheet Resistance}

The wafer coated with $\mathrm{Cr} / \mathrm{Ag} / \mathrm{Au}$ layered electrode showed mirror-like surface after all thermal processed, and the sheet resistance along with the processes is shown as figure 1 . The results showed the similar behavior to $\mathrm{Cr} / \mathrm{Au}$ layered electrode as shown in figure 2. Both $\mathrm{Cr} / \mathrm{Ag} / \mathrm{Au}$ and $\mathrm{Cr} / \mathrm{Au}$ layered electrodes showed sheet resistance increased after $295{ }^{\circ} \mathrm{C}$ vacuum annealing, we think this is because diffusion of $\mathrm{Cr}$ atoms into Au layer as described in [7], the $\mathrm{Cr}$ diffuse into Au when the annealing temperature over $270{ }^{\circ} \mathrm{C}$, because the thermal process temperature after annealing is lower than $270{ }^{\circ} \mathrm{C}$ and annealing temperature, so we can see the sheet resistance average value become stable after annealing process.

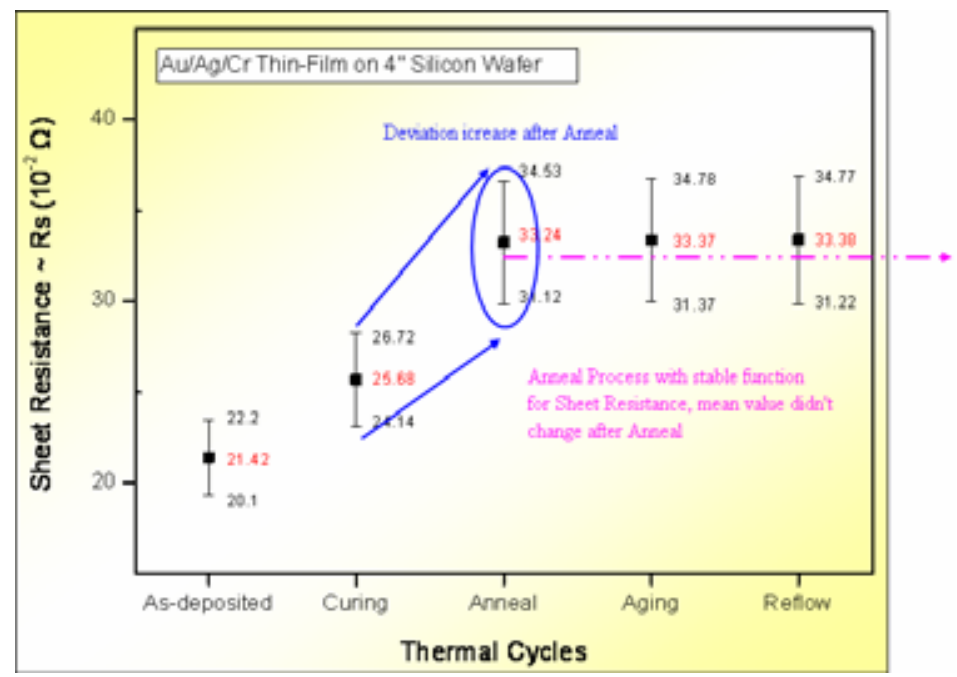

Figure 1 Sheet Resistance of $\mathrm{Cr} / \mathrm{Ag} / \mathrm{Au}$ layered electrode along with processes

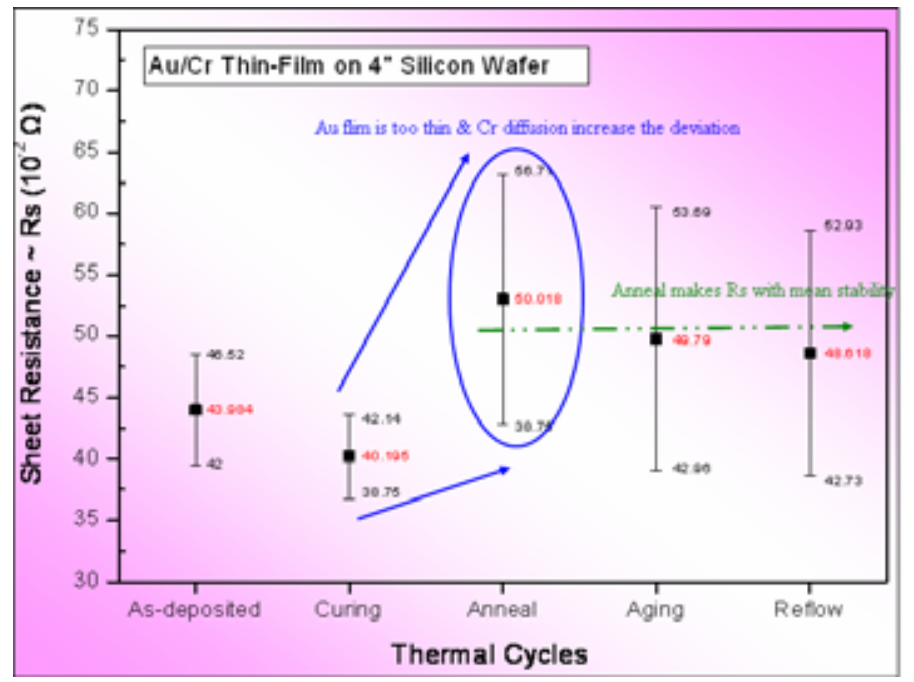

Figure 2 Sheet Resistance of $\mathrm{Cr} / \mathrm{Au}$ layered electrode along with processes

\section{Electrical Performance}

The electrical performance of $\mathrm{Cr} / \mathrm{Ag} / \mathrm{Au}$ electrode crystals is very similar to $\mathrm{Cr} / \mathrm{Au}$, including 
frequency, equivalent series resistance, temperature test, spurious responses. Figure 3 shows the statistical distribution of the equivalent series resistance and figure 4 shows the counterpart of $\mathrm{Cr} / \mathrm{Au}$ layered electrode. The results show $\mathrm{Cr} / \mathrm{Ag} / \mathrm{Au}$ layer electrode resistance is a little lower than $\mathrm{Cr} / \mathrm{Au}$ ones.

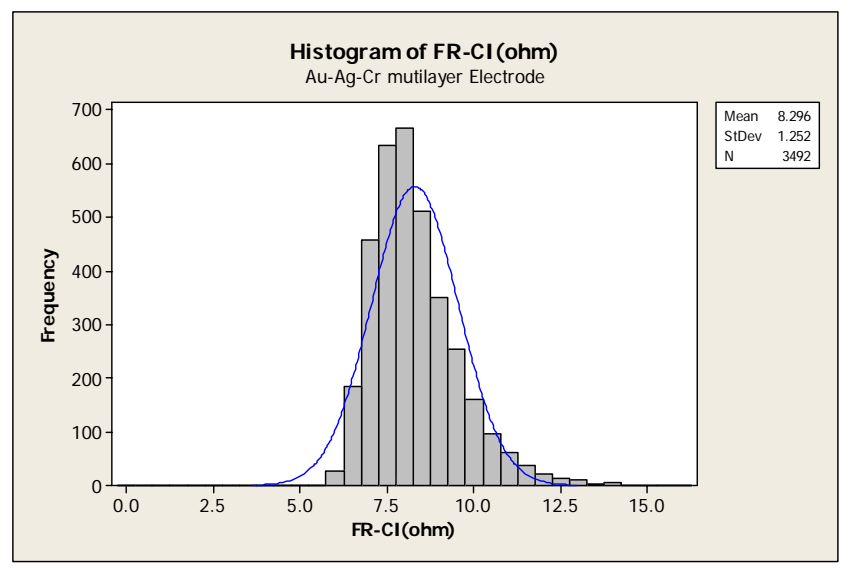

Figure 3 Equivalent Series Resistance distribution of $\mathrm{Cr} / \mathrm{Ag} / \mathrm{Au}$ electrode crystals(26MHz, 5.0 x $3.2 \mathrm{~mm})$

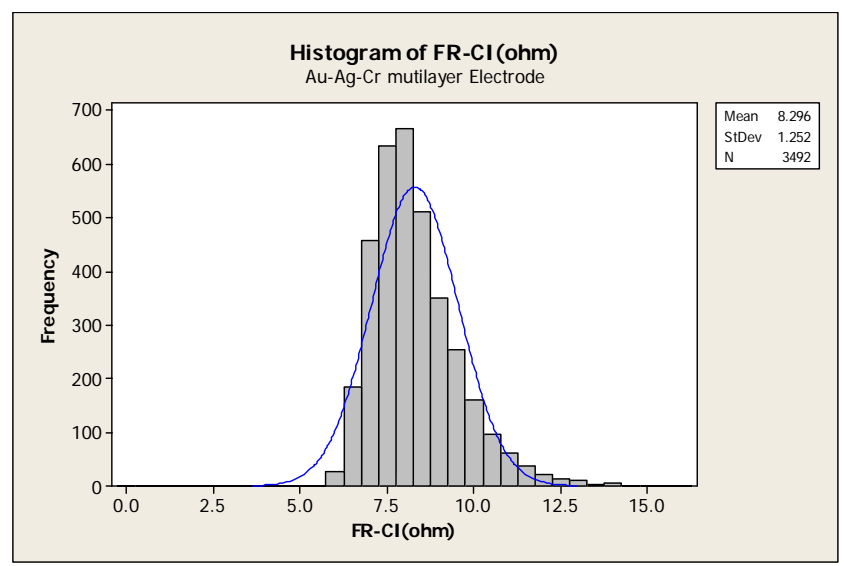

Figure 4 Equivalent Series Resistance distribution of $\mathrm{Cr} / \mathrm{Ag} / \mathrm{Au}$ electrode crystals(26MHz, 5.0 x $3.2 \mathrm{~mm})$

\section{Reliability Performance}

\section{Reflow Test}

The reflow test result is shown in figure 5 , the frequency and equivalent series resistance shift between before and after reflow test is lower than $1 \mathrm{ppm}$ and $10 \mathrm{hm}$, which meet the requirement of mobile phone applications.
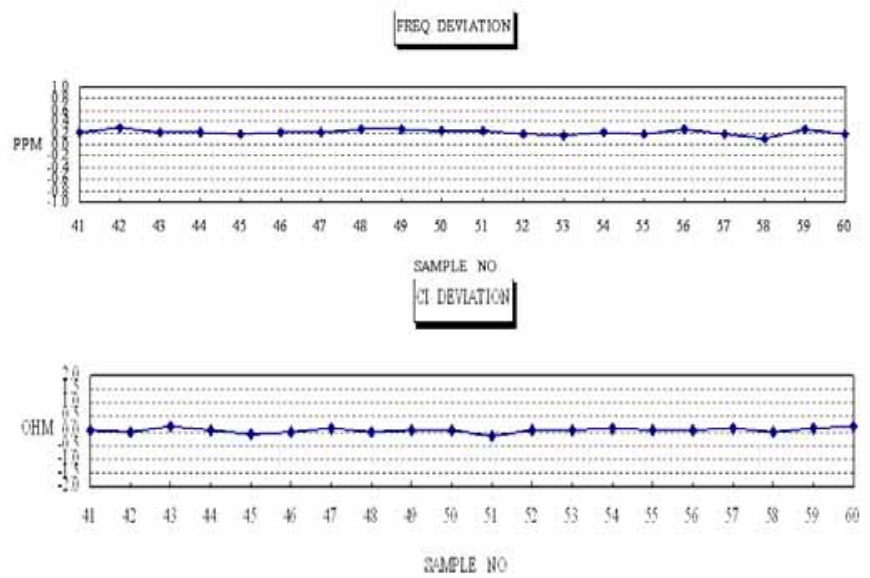

Figure 5 The frequency and ESR shift due to Reflow Test (all samples are within 1ppm, 1 Ohm)

\section{Thermal Shock Test}

The results for thermal shock test(test condition: $-55^{\circ} \mathrm{C}$ to $125^{\circ} \mathrm{C}$, Dwell time $10 \mathrm{~min}$, transit time 20 $\mathrm{sec}$ ) are shown in figure 6 , all the samples show the frequency and ESR shift are within 1ppm and $10 h m$.

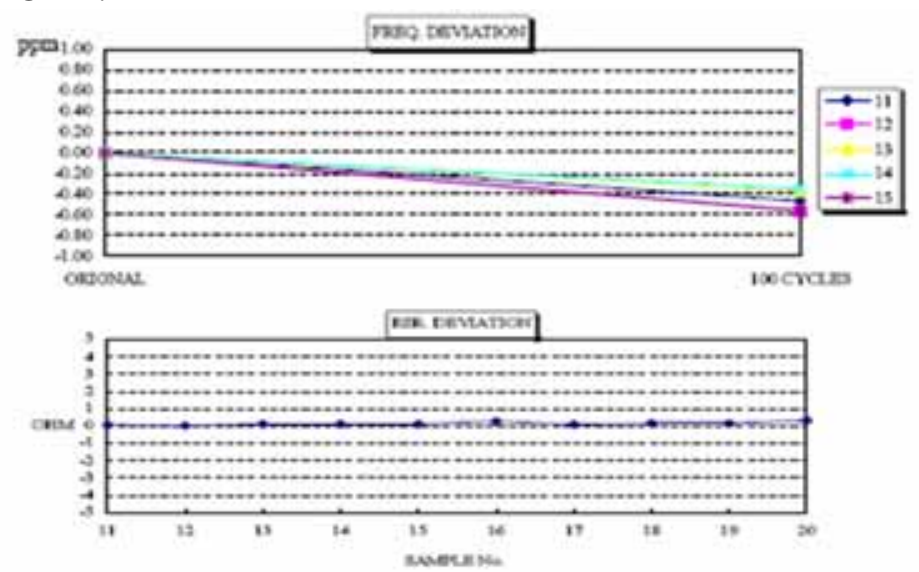

Figure 6 The frequency and ESR shift due to Thermal Shock Test (all samples are within 1ppm, 1 Ohm)

\section{High Temperature \& Humidity Test}

The results for high temperature and humidity test(test condition: temperature $85^{\circ} \mathrm{C}$ and relative humidity $85 \%$, test time 336 ) are shown in figure 7 , all the samples show the frequency and ESR shift are within $1 \mathrm{ppm}$ and $10 \mathrm{hm}$. 

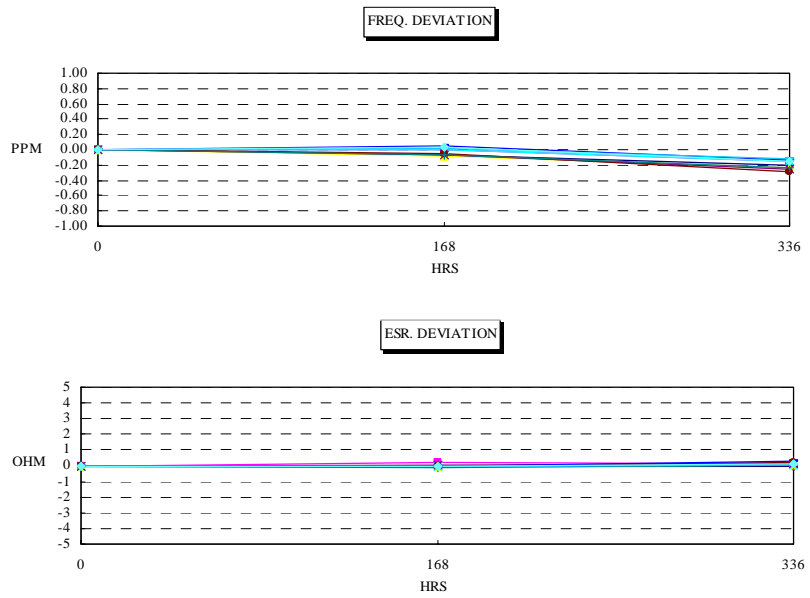

. Figure 7 The frequency and ESR shift due to High Temperature and High Humidity Test (all samples are within 1ppm, 1 Ohm)

\section{CONCLUSION}

Preliminary results show that AT-cut quartz crystal resonators with electrodes based on the $\mathrm{Cr} / \mathrm{Ag} / \mathrm{Au}$ layered structure meet the long-term frequency stability requirement for mobile phone application. The electrical characteristics are compatible to the $\mathrm{Cr} / \mathrm{Au}$ baseplated crystal resonators. The physical characteristics, electrical sheet resistance, study shows that the $\mathrm{Cr} / \mathrm{Ag} / \mathrm{Au}$ layered structure is stable under related thermal process environments.

\section{REFERENCES}

[1] Joe Osha, Andrew Griffin, Srini Pajjuri, Mark Heller, CFA, Jonathan Crossfield and Jonah Cheng, Semiconductor Industry, 26 Oct. 2006.

[2] Osamu Nakagawara, Masahiko Saeki, Akihiro Teramoto, Masayuki Hasegawa, and Hideharu Ieki, "High Power Durable SAW Filter with Epitaxial Aluminum Electrodes on 38.5 Rotated Y-X LiTaO3 by two-step Process Sequence in Titanium Intermediate Layer”, 2003 IEEE Freq. Control. Symp., pp.1734-1737.

[3] T. Nishihara, H. Uchishiba, T. Matsuda, 0. Ikata, and Y. Satoh, "Improvement in Power Durability of SAW Filters”, 1995 IEEE Freq. Control. Symp., pp. 383-388.

[4] R.Takayama, H.Nakanishi, T.Sakuragawa, T.Kawasaki and K.Nomura, "High Power Durable Electrodes for $\mathrm{GHz}$ Band SAW Duplexers, ” 2000 IEEE Freq. Control. Symp.

[5] T. Yokoyama, T. Nishihara, S. Taniguchi, M. Iwaki, and Y. Satoh, M. Ueda and T. Miyashita, "New Electrode Material for Low-loss and High-Q FBAR Filters,” 2004 IEEE Freq. Control. Symp., pp. 429-432.

[6] L. Burianova, J.Nosek, "Composite Structure of Piezoelectric Quartz Resonators,” 2002 IEEE Freq. Control. Symp., pp. 136-140.

[7] Masako Tanaka " The diffusion phenomena in annealed Gold films with various undercoated metals on crystal quartz." Proc. 28th EM Symposium, pp. 35-40, 1999. 